\title{
Cataractogenesis after Repeat Laser in situ Keratomileusis
}

\author{
Ahmad M. Mansour ${ }^{a, b}$ Marwan Ghabra \\ ${ }^{a}$ Department of Ophthalmology, American University of Beirut, and \\ ${ }^{b}$ Department of Ophthalmology, Rafic Hariri University Hospital, Beirut, \\ Lebanon; 'Dar Oyoun Hospital, Damascus, Syria
}

\section{Key Words}

Photorefractive keratectomy · Excimer laser · Cataract · Cataractogenesis · Ultraviolet radiation - Oxidative stress $\cdot$ Refractive surgery complication

\begin{abstract}
There has been the unsubstantiated clinical impression that laser refractive surgery accelerates cataract development along with solid experimental data about the cataractogenic effects of excimer laser treatment. We present the first documented case of significant cataract formation in a young myope after repeat excimer laser ablation necessitating phacoemulsification with a posterior chamber implant. Proposed explanations include focusing of the ablation wave on the posterior capsule (acoustic wave lens epithelial damage), photooxidative stress of the lens (ultraviolet and inflammatory oxidative stress), and corticosteroid-induced cataract (lens toxicity).
\end{abstract}

\section{Introduction}

Since its development by Pallikaris in 1990, laser in situ keratomileusis (LASIK) is currently one of the most popular corneal refractive surgery. It consists of creating a corneal flap and repositioning it after stromal ablation with an excimer laser. LASIK complications have included irregular short flap, incomplete cut, free cap, perforated lenticule, decentration, epithelial ingrowth, wrinkles, haze [1], interface keratitis [2], macular hole [3], and retinal detachment [4]. The excimer laser is an ultraviolet laser with a wavelength of $193 \mathrm{~nm}$. The maximal corneal penetration of the excimer laser is 1-3 $\mu \mathrm{m}$; hence, it has been assumed that it could not cause cataract formation. Very little is known about the clinical effect of LASIK on the lens status. Kato et al. [5] followed up 402 patients ( 779 eyes) with a mean age of 35 years for a period of 5 years after LASIK. Cataract progression was noted in 3 eyes of 2 patients [5]. There has been the question of whether laser refractive surgery accelerates cataract development. Also anecdotal reports of cataracts arising shortly after LASIK (LASIKcomplications.com), 
especially in young subjects, have suggested a cause-effect relationship. We present a case that sheds some light on this controversy.

\section{Case Report}

A 24-year-old man had an initial refractive error of -3.50 in the right eye and $-3.0+0.50 \times 151^{\circ}$ in the left eye. LASIK was performed on February 16, 2008, with a flap size of $6.5 \mathrm{~mm}$ bilaterally and using the Allegretto Wave ${ }^{\circledR}$ Eye-Q $400 \mathrm{~Hz}$ (Wavelight AG, Erlangen, Germany). After surgery, flumetholone $0.1 \%$ was prescribed 5 times daily for 2 weeks. Postoperatively, uncorrected vision was $6 / 6(20 / 20)$ in the right eye and 6/7.5 (20/25) in the left eye. On August 21, 2011, cycloplegic refraction revealed emmetropia in the right eye and +3.50 in the left eye with vision corrected to $6 / 6$ $(20 / 20)$ using +2.50 . On August 29, 2011, the flap was raised and excimer laser applied. The patient was treated with loteprednol etabonate $0.5 \%$ and tobramycin $0.3 \%$ eye drops for 2 weeks. On November 16, 2011, he complained of blur and discomfort in the left eye. He had mild corneal inflammation at the LASIK interface. The inflammation resolved after 2 weeks of dexamethasone antibiotic preparation (dexamethasone $1 \mathrm{mg} / \mathrm{ml}$, neomycin sulfate 3,500 IU/ml, and polymyxin B sulfate $6,000 \mathrm{IU} / \mathrm{ml} 3$ times daily), reaching an unaided visual acuity of $6 / 12(20 / 40)$ and 6/6 (20/20) with -1.50 . The examination on February 29,2012 , revealed a best corrected visual acuity of $6 / 21$ $(20 / 70)$ with anterior and posterior epinuclear haziness. Further worsening of the cataract was observed over 2 weeks of observation with a visual loss to 6/60 (20/200). He underwent phacoemulsification with a foldable intraocular implant on April 13, 2012. Trypan blue dye staining was necessary to visualize the anterior capsule. Globule formation or droplets were noted during capsulorhexis at the cortical-nuclear interface. There was no posterior subcapsular cataract. Uncorrected vision was 6/6 (20/20) at 1, 3 and 12 weeks after cataract surgery.

\section{Discussion}

Posterior subcapsular cataract is a type of lens opacification occurring in $6 \%$ of all adults between the ages of 43 and 84 years in the Beaver Dam Eye Study [6]. It may be caused by a variety of conditions: uveitis, degenerative chorioretinal diseases, and impaired ocular circulation. Prolonged use of glucocorticoids is a significant risk factor for the development of posterior subcapsular cataract. While the cataractogenic effects of corticosteroids are beyond dispute, disagreement exists concerning the effects of total dose, intensity of dose, and duration of administration on cataract formation [7]. In the present case, posterior subcapsular cataract was absent. Instead, there was diffuse and progressive perinuclear haze with globules. Steroid-induced posterior subcapsular cataracts exhibit distinctive characteristics (prolonged use of the steroid [7] and a central posterior location [8]) that were absent in our case; hence, corticosteroids may be minor players in the etiology of cataract in the current case.

Occasionally, one may develop, as in our patient, inflammation between the flap and corneal bed, especially after LASIK enhancement. Such inflammation is usually eliminated with the use of potent and frequent corticosteroid eye drops. Some inflammation of the cornea after LASIK is normal, but if uncontrolled, it can interfere with healing and cause visual loss as in diffuse lamellar keratitis [2].

The potential cataractogenic effects of LASIK are summarized in table 1 [7, 9-14] and include mainly anterior segment inflammation, acoustic wave injury, and photooxidative stress. Wachtlin et al. [12] noted that the inflammation in the anterior chamber after LASIK was induced by the microkeratome incision rather than by the excimer laser; in addition, Krueger et al. [11] measured the stress wave amplitudes in 
porcine eyes generated during excimer photoablation. They found that the pressure focus was located in the posterior lens where amplitudes of up to $100 \mathrm{~atm}$ were measured [11]. Costagliola et al. [13] analyzed the photooxidative stress induced by excimer laser treatment on a rabbit lens. The rabbit lens evidenced a significant increase in hydrogen peroxide and oxidized glutathione levels ( 2 radical donors) at 1 week and 1 month after excimer ablation. This increase in the radical donors correlated with the cumulative ultraviolet dose used [13]; hence, repeat excimer corneal ablation carries a higher risk of oxidative lens damage. Similar deleterious effects on lens proteins were documented after excimer laser ablation in rabbits by gel electrophoresis [9]. Lens opacification started at the interface between the nucleus and the cortex in rats exposed to oxidative stress (similar to the current case) [15], in the form of cell swelling and globule formation. Our case had no evidence of penetration into the anterior chamber. We hypothesize that a combination of photooxidative stress and acoustic stress wave from repeat excimer laser usage, in addition to some toxic effect of topical corticosteroids, led to ultimate damage to the lens epithelial cells, causing anterior and posterior epinuclear opacification.

\section{Disclosure Statement}

The authors have no proprietary interests in any product mentioned.

Table 1. Potential cataractogenic factors of LASIK

1 Steroid induced [7]

2 Anterior segment ischemia during extreme increase in intraocular pressure during suction, especially when this step is prolonged

3 Iatrogenic corneal penetration into the anterior chamber, especially in repeat surgery [10]

4 Inflammation of the anterior segment, possibly from microkeratome [12]

5 Photooxidative stress on the anterior segment and lens proteins $[9,13]$

6 Focusing of the ablation wave of the excimer laser or acoustic waves on the posterior capsule, leading to damage to the posterior capsule $[11,14]$ 


\section{References}

-1 Farah SG, Azar DT, Gurdal C, Wong J: Laser in situ keratomileusis: literature review of a developing technique. J Cataract Refract Surg 1998;24:989-1006.

-2 Gritz DC: LASIK interface keratitis: epidemiology, diagnosis and care. Curr Opin Ophthalmol 2011;22:251-255.

-3 Arevalo JF, Mendoza AJ, Velez-Vazquez W, Rodriguez FJ, Rodriguez A, Rosales-Meneses JL, Yepez JB, Ramirez E, Dessouki A, Chan CK, Mittra RA, Ramsay RC, Garcia RA, Ruiz-Moreno JM: Full-thickness macular hole after LASIK for the correction of myopia. Ophthalmology 2005;112:1207-1212.

-4 Arevalo JF, Ramirez E, Suarez E, Cortez R, Ramirez G, Yepez JB: Retinal detachment in myopic eyes after laser in situ keratomileusis. J Refract Surg 2002;18:708-714.

5 Kato N, Toda I, Hori-Komai Y, Sakai C, Tsubota K: Five-year outcome of LASIK for myopia. Ophthalmology 2008;115:839-844.

-6 Gwon A, Mantras C, Gruber L, Cunanan C: Concanavalin A-induced posterior subcapsular cataract: a new model of cataractogenesis. Invest Ophthalmol Vis Sci 1993;34:3483-3488.

7 Skalka HW, Prchal JT: Effect of corticosteroids on cataract formation. Arch Ophthalmol 1980;98:17731777.

8 James ER: The etiology of steroid cataract. J Ocul Pharmacol Ther 2007;23:403-420.

-9 Abdelkawi SA, Ghoneim DF, Atoat W, Badr YA: $193 \mathrm{~nm}$ ArF excimer laser and the potential risk for cataract formation. Journal of Applied Sciences Research 2010;6:796-805.

10 Nakamura K, Bissen-Miyajima H, Arai H, Toda I, Hori Y, Shimmura S, Tsubota K: Iatrogenic cataract after laser-assisted in situ keratomileusis. Am J Ophthalmol 1999;128:507-509.

11 Krueger RR, Seiler T, Gruchman T, Mrochen M, Berlin MS: Stress wave amplitudes during laser surgery of the cornea. Ophthalmology 2001;108:1070-1074.

12 Wachtlin J, Blasig IE, Schründer S, Langenbeck K, Hoffmann F: PRK and LASIK their potential risk of cataractogenesis: lipid peroxidation changes in the aqueous humor and crystalline lens of rabbits. Cornea 2000;19:75-79.

13 Costagliola C, Balestrieri P, Fioretti F, Frunzio S, Rinaldi G, Scibelli G: Arf 193 nm excimer laser corneal surgery and photo-oxidative stress in aqueous humor and lens of rabbit: one-month follow-up. Curr Eye Res 1996;15:355-361.

14 Uteza O, Delaporte P, Fontaine B, Forestier B, Sentis M, Tassy I, Truong JP: Acoustic wave origin in excimer lasers. Appl Phys B 1997;64:531-537.

15 Marsili S, Salganik RI, Albright CD, et al: Cataract formation in a strain of rats selected for high oxidative stress. Exp Eye Res 2004;79:595-612. 